\title{
ROAP Regimen
}

National Cancer Institute

\section{Source}

National Cancer Institute. ROAP Regimen. NCI Thesaurus. Code C10036.

A chemotherapy regimen consisting of zorubicin, vincristine, cytarabine, and prednisone, that may be used in the treatment of acute myeloid leukemia (AML). 